\title{
Defining a Test for HER-2/neu Evaluation in Breast Cancer in the Diagnostic Setting
}

Wedad M. Hanna, M.D., Harriette J. Kahn, M.D., Margaret Pienkowska, Ph.D., John Blondal, M.D., Arun Seth, Ph.D, Alexander Marks, Ph.D

Sunnybrook and Women's College Health Sciences Centre, Departments of Pathology (WMH, HJK, MP, AS), Medicine (JB), and Banting and Best Departments of Medical Research (AM), University of Toronto,

Toronto, Ontario, Canada

In breast cancer amplification of the HER-2/neu oncogene and over-expression of the protein product is associated with poor prognosis, predicts response to some chemotherapeutic regimens and is the target for Herceptin treatment. To date there are several methods to assess the amplification/overexpression of HER-2/neu with each having advantages and disadvantages. We have studied amplification and over-expression of HER-2/neu in 250 consecutive cases of breast cancer ( 220 invasive and 30 in situ carcinomas) presenting to the Department of Pathology at Women's College Campus of Sunnybrook and Women's College Health Sciences Center. Thirty percent of the invasive carcinomas were node positive. HER-2/neu protein overexpression was assessed by immunohistochemistry (IH) using antibody CB11 and amplification of the gene by differential PCR. The percentage of tumor cells showing CB11 staining was determined and the most significant cut off point for positivity was $\geq 10 \%$ moderate or strong complete membranous staining. The gene was considered amplified if the density score of the product was $\geq 2$. There was $94 \%$ concordance between the two methods ( $P$ value $.0001)$. Both methods were positive in $16 \%$ of cases and negative in $78 \%$ of cases. Discrepant cases were examined by FISH which confirmed the IH results in 9/11 invasive carcinomas. These results show that there is excellent concordance between IH and PCR. However, immunohistochemistry is easier to perform and cheaper than PCR and could be used in routine assessment of HER-2/neu in breast cancer patients.

Copyright () 2001 by The United States and Canadian Academy of Pathology, Inc.

VOL. 14, NO. 7, P. 677, 2001 Printed in the U.S.A

Date of acceptance: March 11, 2001

Address reprint requests to: Wedad M. Hanna, M.D., Anatomic Pathology, Women's College Campus, Sunnybrook and Women's College Health Sciences Centre, 76 Grenville Street, Toronto, Ontario, Canada, M5S 1B2; e-mail: wedad.hanna@swchsc.on.ca.
KEY WORDS: Breast Cancer, HER-2/neu, IHC, PCR. Mod Pathol 2001;14(7):677-685

Breast cancer results from molecular alterations that are genetically and/or environmentally induced resulting in uncontrolled cell proliferation. One of the significant molecular alternations noted is amplification of the HER-2/neu gene that occurs in $20-30 \%$ of cases. This marker has been extensively studied and it has been shown that HER2 is a significant prognostic marker in both node positive and node negative breast cancer patients. Equally important is the predictive role of this marker in identifying patients that will or will not respond to hormonal or some chemotherapeutic regimens. The significance of HER-2/neu as a prognostic or predictive marker in breast cancer has been addressed in two literature reviews $(1,2)$. The role of HER-2/neu has been extended with the release of Herceptin, a humanized antibody against HER-2/ neu that is being used to treat breast cancer patients (3). The drug was released in the US in 1998, in Canada in the fall of 1999 and will be released in Europe in 2000.

In spite of the release of the drug there is no agreement as to the best method of assessing amplification and/or over-expression of HER-2/neu gene. There is also great variation in the published data vis-a-vis the scoring systems and the positive cut off points used $(1,2)$. HER-2/neu can be measured in different ways: 1) Oncoprotein over-expression: This could be performed by immunohistochemistry (IH) on either frozen or paraffin embedded tissue sections using monoclonal or polyclonal antibodies to the $185 \mathrm{kd}$ protein or the phosphorylated product; by ELISA (using cytosol or serum) or by Western blot. 2) Gene amplification: This could be performed by Southern hybridization; by polymerase chain reaction (PCR) (competitive, differential or real time); or by fluorescence in situ hybridization (FISH). 3) mRNA by Northern blot. 
The Herceptin efficacy phase 2 and 3 trials, utilized a cocktail of two antibodies (CB11 and D5) to assess HER-2/neu status by immunohistochemistry (CTA) (3). They considered the case positive when weak to moderate $(2+)$ or strong staining $(3+)$ was seen in $10 \%$ of cells in a membranous pattern. Dako produced a polyclonal antibody and compared the immunohistochemical results with their antibody to the CTA antibodies in a different subset of patients. There was $79 \%$ overall concordance between results obtained with the CTA and Dako antibodies using 580 breast cancer specimens that differed from the ones used in the phase 2 and 3 trials of Herceptin. Forty two percent of cases in the 2+ category were discordant with the CTA results. In addition, 168 cases were examined for gene amplification and protein over-expression and the results compared with the Dako HercepTest. This showed a positive agreement of $62 \%$ and a negative agreement of $100 \%$ indicating that there was a significant number of false positive cases (Dako Press Release). Penault-Llorca (4) et al. compared the results of HER-2/neu testing in 58 tumors using different methods, different fixatives and different antibodies: Tab250, 9G6, NCL CB11 and OA-11-854. Their results showed than on paraffin sections NCLCB11 and Tab250 offered a good balance between sensitivity and specificity although CB11 was better on frozen tissue and Tab250 was most consistent in tissue fixed in phosphate buffered formalin. They also found that alcoholic formalin appeared to be the best fixative for HER-2/neu immunodectection.

We undertook a study to establish a reproducible, sensitive and specific method for testing for HER$2 /$ neu that could be used in diagnostic pathology laboratories. We compared IH detection of HER-2/ neu protein with differential PCR to assess gene amplification. FISH was used as the gold standard to resolve discrepant cases. We selected PCR instead of FISH for comparison with IH since it is less subjective in defining the copy number and could be automated to study large numbers of cases. In addition, assessment of appropriate cut off points were established.

\section{MATERIALS AND METHODS}

Two hundred and fifty consecutive cases of in situ and invasive breast cancer were prospectively examined during 1998 in the Department of Pathology at Women's College Campus of Sunnybrook and Women's College Health Sciences Center in Toronto. These included 220 invasive and $30 \mathrm{in} \mathrm{situ}$ breast cancers. Thirteen of the invasive carcinomas were locally recurrent. Of the primary invasive cancers, 196 were infiltrating duct, 5 infiltrating lobular and 6 mucinous carcinomas. The nodal status of the 207 cases of primary invasive cancer was known. The tissue was fixed in $10 \%$ buffered formalin and usually processed within 24 hours.

\section{Immunohistochemical assay}

Immunohistochemical staining was performed on formalin fixed, paraffin embedded tissue sections of each case using the monoclonal antibody CB11 to the HER-2/neu oncoprotein (Nova Castra Laboratories, UK). After deparaffinization, endogenous peroxidase was blocked using 3\% hydrogen peroxide. The primary antibody was applied at a 1:50 dilution for 2 hours followed by the BiotinStreptavidin peroxidase complex. 3.3' diaminobenzidine was used as the chromagen. The slides were counterstained with Harris's hematoxylin.

The percentage of tumor cells showing either a complete or partial membranous pattern was scored in each case. The intensity of membrane staining was assessed as strong, moderate or weak. Strong membranous staining was easily seen at low magnification (Fig 1a). Weak staining was pale and not clearly visible at $400 \times$ magnification (Fig 1b). Moderate staining was less intensive than strong staining but easily visible at $400 \times$ magnification (Fig. 1c). Partial membrane staining was defined as incomplete positivity around the membrane of a cell (Fig. 1b).

\section{PCR}

We used a competitive PCR method to assess the average number of HER-2/neu gene copies, using asparagine synthase (AS) as a reference gene. A parallel 10 micron section of the same block was assessed for gene amplification using differential PCR. One hundred nanograms of target DNA was used in each determination. The HER-2/neu primers (neu 1 5[prime]-CTC ACA ACC AAG TGA GGC AG-3[prime] and neu ${ }_{2} 5$ [prime]-CAG GGG TGG TAT TGT TCA GC-3 [prime]) were used at a concentration of $0.8 \mathrm{um}$. The control gene (AS) primers $\left(\mathrm{AS}_{1}\right.$ 5[prime]-ACA TTG AAG CAC TCC GCG AC-3[prime] and $\mathrm{AS}_{2}$ 5[prime]-CCA CAT TGT CAT AGA GGG CG-3[prime]) were used at a concentration of 0.4 uM. Differential PCR was performed on Perkin Elmer Cetus Thermal Cycler-480. Touchdown PCR technique was used to improve PCR specificity by decrementing the annealing temperature during initial cycles, starting at $60^{\circ} \mathrm{C}$, and arriving at a "touchdown" temperature of $50^{\circ} \mathrm{C} .20 \mu \mathrm{l}$ of the PCR reaction solution was separated by electrophoresis on $4 \%$ agarose gel, stained with ethidium bromide, and imaged on a Vector Bio-system imaging system. The fluorescent density of resulting amplicon bands was assessed using the ImagequaNT Software Version 4.2. HER-2/neu gene amplification 

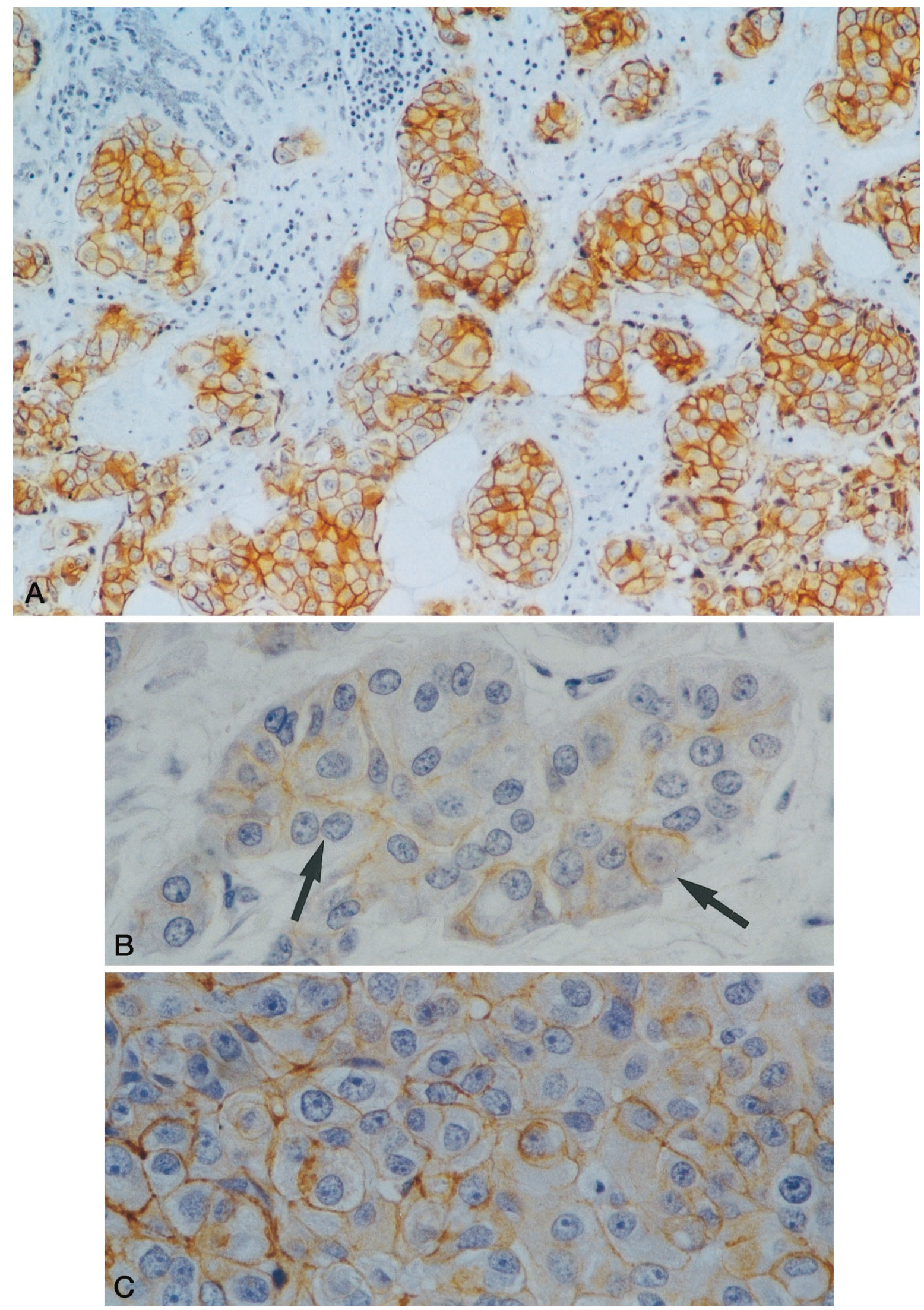

FIGURE 1. A, Invasive ductal carcinoma showing diffuse strong complete membranous staining for HER-2/neu (mag $\times 100$ ). B, Invasive ductal carcinoma showing weak incomplete membranous staining for HER-2/neu (arrows) (mag $\times 400$ ). C, Invasive ductal carcinoma showing variable intensity of membrane staining. Some cells show moderate staining and others showing weak staining for HER-2/neu (mag $\times 400)$. 
copy number was determined by comparing the ratio of HER2:AS amplicon density to the established calibration curve generated from similar ratios plotted against known HER-2/neu gene copy numbers in using breast cancer cell-line DNA.

A standard curve of HER-2/neu gene copy number against HER-2/neu:AS PCR amplicon ratios was generated using cell-lines, SKBR-3, T47-D and normal spleen DNA giving 10, 3 and 1 HER-2/neu copies respectively. Serial dilutions of DNA from SKBR-3 cell-line was performed to obtain additional data points.

For PCR the ratio of HER2:AS amplicon density of each case was recorded and interpreted as follows: $\geq 2$ is amplified, less than 2 not amplified.

\section{$\mathrm{FISH}$}

FISH analysis was performed on formalin fixed paraffin sections on 28 of cases which included amplified, not amplified and all the discrepant cases using the Vysis probe (Intermedico) according to the method described by Pauletti et al. (5) and according to the manufacturer's specifications. The results were scored as follows: $2-4$ copies $=$ not amplified, $\geq 5$ copies $=$ amplified. In addition, the number of copies of chromosome 17 was evaluated to assess ploidy and the ratio of HER-2/neu gene copies to the number of chromosome 17 noted. A ratio $\geq 2$ was considered amplified.

Thirteen randomly selected positive and negative concordant cases from this series were studied by FISH. Twenty previous cases of breast cancer that were concordant by PCR, IH and FISH were used as controls.

\section{Statistical Analysis}

Statistical analysis was performed using Fisher's exact test. Regression analysis was carried out for comparison of the HER-2/neu protein overexpression by IH and amplification of the gene by differential PCR.

\section{RESULTS}

IH showed either complete membranous staining (Fig. 1a) partial membrane staining (Fig. 1b) and/or cytoplasmic staining. The intensity of membrane staining was either weak, moderate or strong (Fig. la, b, c). Linear correlation of results between PCR and IH showed that the best concordance was obtained using $10 \%$ complete membrane staining and moderate or strong intensity of staining as the cut off point for positivity for IH and $\geq 2$ density

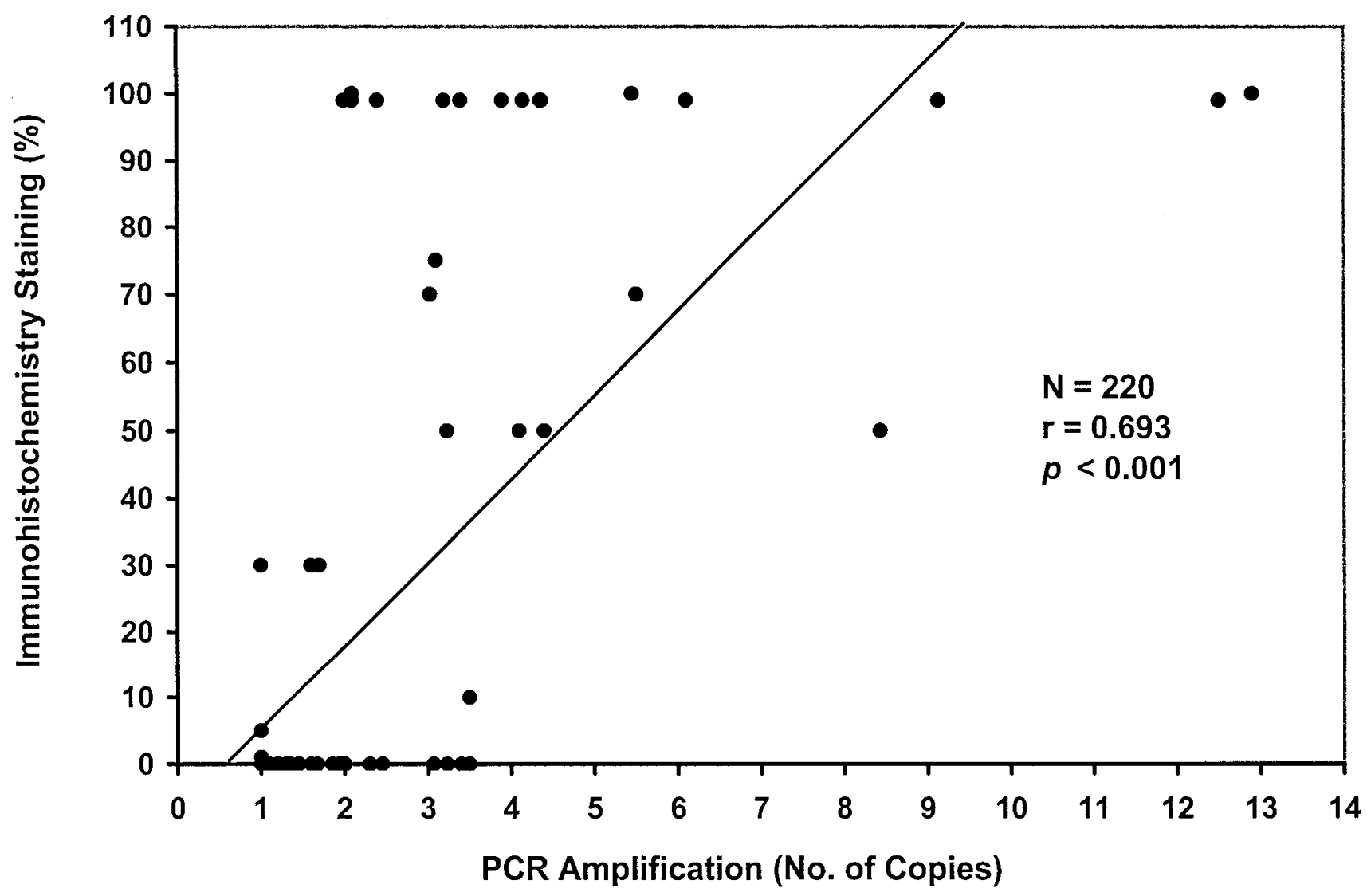

FIGURE 2. Relationship between IH and PCR for HER-2/neu detection in invasive breast cancer. 
score for PCR (Fig. 2). Although our graph shows that the cut point is $15 \%$ complete membrane staining we opted for $10 \%$ for practical reasons. Moderate to strong complete membrane staining was noted in 44/250 cases. Twelve cases with weak staining and/or partial membrane staining were considered negative. When partial membrane staining was present it was noted in less than $10 \%$ of tumor cells. Cytoplasmic staining alone did not correlate with gene amplification. Figure 3 illustrates cases positive and negative for HER-2/neu amplification.

The overall concordance between IH and PCR for all 250 cases (invasive and in situ breast carcinoma) was $94 \%$ (Table 1). Of the 235 cases that were concordant, 41 (16\%) of cases were positive and 194 $(78 \%)$ of cases were negative by both methods. The HER-2/neu status of 13/235 concordant cases (9 positive and 4 negative) were confirmed using FISH (Fig. 4).

The overall concordance between IH and PCR of the 220 invasive breast cancer was $95 \%$. Of the 209 concordant cases, 32 (14.5\%) were IH and PCR positive whereas $177(80.5 \%)$ were negative by both methods. Of the 11 discordant cases 8 (4\%) were IH negative and PCR positive, and FISH was positive in 2 out of these 8 cases. All 3 cases that were $\mathrm{IH}$
positive/PCR negative were FISH positive. These results indicate that using FISH as the gold standard, 3/11 cases were false negative and 6 were false positive by PCR, whereas $2 / 11$ cases were false negative by $\mathrm{IH}$ and none of the cases were false positive by IH.

The sensitivity of CB11 as compared with PCR in the invasive cancer was $80 \%$ and the specificity $98 \%$. The positive predictive value was $91 \%$ and the negative predictive value was $96 \%$.

Amplification and/or over-expression of HER-2/ neu was associated with the invasive ductal carcinoma phenotype. None of the 5 invasive lobular carcinomas showed HER-2/neu amplification or over-expression of the protein whereas $1 / 6$ mucinous carcinomas showed amplification and overexpression of HER-2/neu.

Twenty six of the $30(87 \%)$ in situ cancers were concordant. Nine cases (30\%) were concordant IH positive/PCR positive and 17 cases (57\%) were concordant IH negative/PCR negative. In the 4 discordant cases FISH results indicated that IH was false negative in $2 / 3$ and false positive in $1 / 1$ case. PCR was false positive in $1 / 3$ cases and there ware no false negatives (Table 1).

Of the 220 invasive cancers, 78 were node positive and 17 (22\%) of these were HER-2/neu positive;

\section{HER2/neu AMPLIFICATION by DIFFERENTIAL PCR}

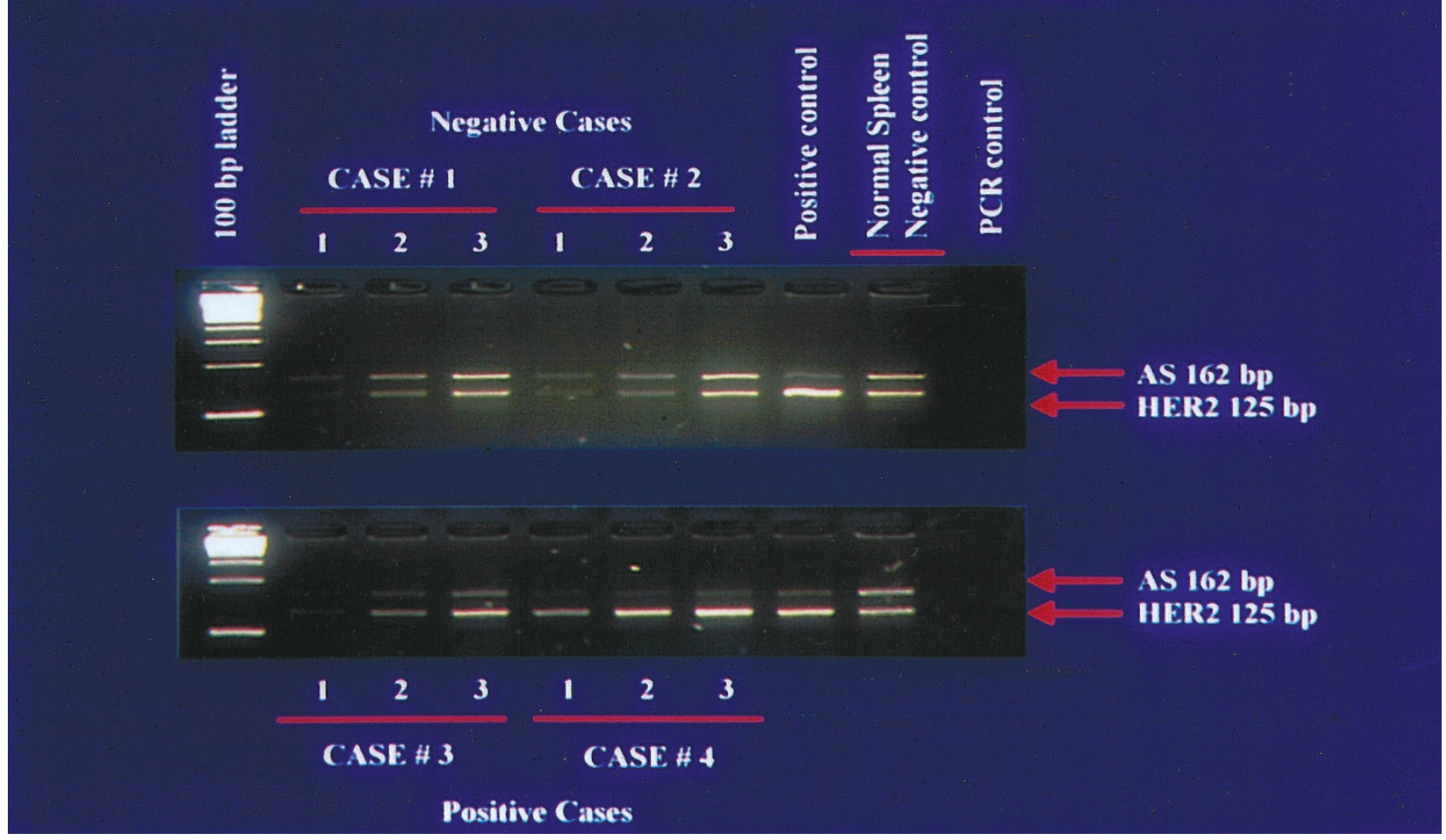

FIGURE 3. PCR results of HER-2/neu amplification in positive and negative cases and controls. Agarose gel image showing HER-2/neu and AS amplified bands, 125 and 162 bp respectively. PCR reactions were done as described in Material and Method section. Samples were analyzed after 26(1), 28(2) and 30(3) cycles of amplification. Negative samples show both the HER-2/neu and AS bands while positive samples show predominance of the HER-2/neu band. Cases 1 and 2 are negative, whereas 3 and 4 are positive for HER-2/neu amplification. 
TABLE 1. Results of HER2/Neu Testing by IH, PCR, and FISH

\begin{tabular}{|c|c|}
\hline \multicolumn{2}{|c|}{ Invasive and in situ breast cancer (250) } \\
\hline \multicolumn{2}{|l|}{ Concordant } \\
\hline \multicolumn{2}{|l|}{ IH/PCR 235} \\
\hline \multicolumn{2}{|l|}{$(94 \%)$} \\
\hline $\mathrm{IH}+/ \mathrm{PCR}+$ & $41(16 \%)$ \\
\hline IH $-/$ PCR - & $194(78 \%)$ \\
\hline \multicolumn{2}{|l|}{ Concordant } \\
\hline \multicolumn{2}{|l|}{ IH/PCR with } \\
\hline \multicolumn{2}{|l|}{ addition of } \\
\hline \multicolumn{2}{|l|}{ FISH (13) } \\
\hline $\mathrm{IH}+/ \mathrm{PCR}+/ \mathrm{FISH}+$ & 9 \\
\hline $\mathrm{IH}-/ \mathrm{PCR}-/ \mathrm{FISH}-$ & 4 \\
\hline \multicolumn{2}{|l|}{ Discordant } \\
\hline \multicolumn{2}{|l|}{$15(6 \%)$} \\
\hline $\mathrm{IH}-/ \mathrm{PCR}+$ & $11(4 \%)$ \\
\hline $\mathrm{IH}+/ \mathrm{PCR}-$ & $4(2 \%)$ \\
\hline \multicolumn{2}{|c|}{ Invasive breast cancer (220) } \\
\hline \multicolumn{2}{|l|}{ Concordant } \\
\hline \multicolumn{2}{|l|}{ IH/PCR 209} \\
\hline \multicolumn{2}{|l|}{$(95 \%)$} \\
\hline $\mathrm{IH}+/ \mathrm{PCR}+$ & $32(14.5 \%)$ \\
\hline $\mathrm{IH}-/ \mathrm{PCR}-$ & $177(80.5 \%)$ \\
\hline \multicolumn{2}{|l|}{ Discordant } \\
\hline \multicolumn{2}{|l|}{$11(5 \%)$} \\
\hline $\mathrm{IH}-/ \mathrm{PCR}+$ & $8(4 \%)$ \\
\hline $\mathrm{IH}+/ \mathrm{PCR}-$ & $3(1 \%)$ \\
\hline \multicolumn{2}{|l|}{ Discordant } \\
\hline \multicolumn{2}{|l|}{ IH/PCR with } \\
\hline \multicolumn{2}{|l|}{ addition of } \\
\hline \multicolumn{2}{|l|}{ FISH (11) } \\
\hline $\mathrm{IH}-/ \mathrm{PCR}+/ \mathrm{FISH}+$ & $2 / 8(1 \%)$ \\
\hline $\mathrm{IH}+/ \mathrm{PCR}-/ \mathrm{FISH}+$ & $3 / 3(1 \%)$ \\
\hline $\mathrm{IH}-/ \mathrm{PCR}+/ \mathrm{FISH}-$ & $6 / 8(3 \%)$ \\
\hline $\mathrm{IH}+/ \mathrm{PCR}-/ \mathrm{FISH}-$ & $0 / 3(0 \%)$ \\
\hline \multicolumn{2}{|l|}{ In situ breast } \\
\hline \multicolumn{2}{|l|}{ cancer (30) } \\
\hline \multicolumn{2}{|l|}{ Concordant } \\
\hline $26(87 \%)$ & \\
\hline $\mathrm{IH}+/ \mathrm{PCR}+$ & $9(30 \%)$ \\
\hline $\mathrm{IH}-/ \mathrm{PCR}-$ & $17(57 \%)$ \\
\hline $\begin{array}{l}\text { Discordant } 4 \\
(13 \%)\end{array}$ & \\
\hline $\mathrm{IH}-/ \mathrm{PCR}+$ & $3(10 \%)$ \\
\hline $\mathrm{IH}+/ \mathrm{PCR}-$ & $1(3 \%)$ \\
\hline Discordant & \\
\hline IH/PCR with & \\
\hline addition of & \\
\hline FISH (4) & \\
\hline $\mathrm{IH}-/ \mathrm{PCR}+/ \mathrm{FISH}+$ & $2 / 3(7 \%)$ \\
\hline $\mathrm{IH}+/ \mathrm{PCR}-/ \mathrm{FISH}+$ & $0 / 1(0 \%)$ \\
\hline $\mathrm{IH}-/ \mathrm{PCR}+/ \mathrm{FISH}-$ & $1 / 3(3 \%)$ \\
\hline $\mathrm{IH}+/ \mathrm{PCR}-/ \mathrm{FISH}-$ & $1 / 1(3 \%)$ \\
\hline
\end{tabular}

IH, immunohistochemistry; PCR, polymerase chain reaction; FISH, fluorescence in situ hybridization.

113 were node negative and 14 (12.5\%) were HER$2 /$ neu positive; in 29 cases axillary dissection was not performed and 5 (17\%) were HER-2/neu positive (Table 2). Only $2 / 13$ recurrent cases expressed HER-2/neu protein, one case was node negative and the other was node positive.

\section{DISCUSSION}

The interest in Herceptin, a humanized monoclonal antibody, stems from the results of randomized phase 3 trials showing that patients whose tumor cells have increased levels of HER-2/neu protein expression do significantly better when Herceptin is added to chemotherapy (3). In addition to its prognostic significance in breast cancer patients, HER$2 /$ neu protein over-expression may gain greater values if current ongoing studies confirm its role in predicting response to hormonal and radiotherapy as well as the type of combination and/or dose of chemotherapy (6-9). However, the utility of this biological marker can be enhanced and better evaluated if we can reach consensus on the appropriate methodology and the most clinically significant cut off points (10).

The principal methods for assessing HER-2/neu status are immunohistochemistry using antibodies to detect over-expression of the protein and molecular techniques specifically PCR or fluorescence in situ hybridization (FISH) to assess amplification of the gene. The marked variability in the specificity and sensitivity of different HER-2/neu antibodies (11) and the variability in interpreting the results $(12,13)$ even when the same antibody is used requires comprehensive standardization studies. In addition, use of frozen versus fixed tissue and the different fixatives used can influence the specificity and sensitivity of the antibodies used (4). According to Paulette et al. the gold standard of choice for HER-2/neu testing is IH on frozen material (5). However, since frozen material is not always available, they demonstrated that FISH is a reliable and reproducible method for testing for HER-2/neu (5).

The standardization of HER-2/neu testing and appropriate cut off points have to be achieved by both technical and clinical validation of the results. This point was well addressed by G. Allred and Swanson in a recent editorial (14). The CTA is the only clinically validated test in predicting response to Herceptin. More recently, the tumors tested by the CTA were assessed by FISH and there was $82 \%$ concordance between the two methods (15).

In our study, moderate or strong complete membranous staining was the significant pattern of HER$2 /$ neu over-expression. Incomplete membrane staining occurred in 12 cases and was not associated with gene amplification. None of the cases showing cytoplasmic staining by IH were amplified by PCR. The significance of cytoplasmic staining seen with CB11 is controversial although most studies agree that it is a nonspecific finding. However, a few studies have demonstrated concordance between strong cytoplasmic staining and poor prognosis in a subset of node positive breast cancer patients (16). Thus for the present time only the membrane pattern of staining should be evaluated.

In this study, the most appropriate cut off points for percentage membrane staining by $\mathrm{IH}$ that resulted in the best concordance between $\mathrm{IH}$ and PCR, was $10 \% P=.0001$. The percentage of cells showing moderate or strong positivity is a more 


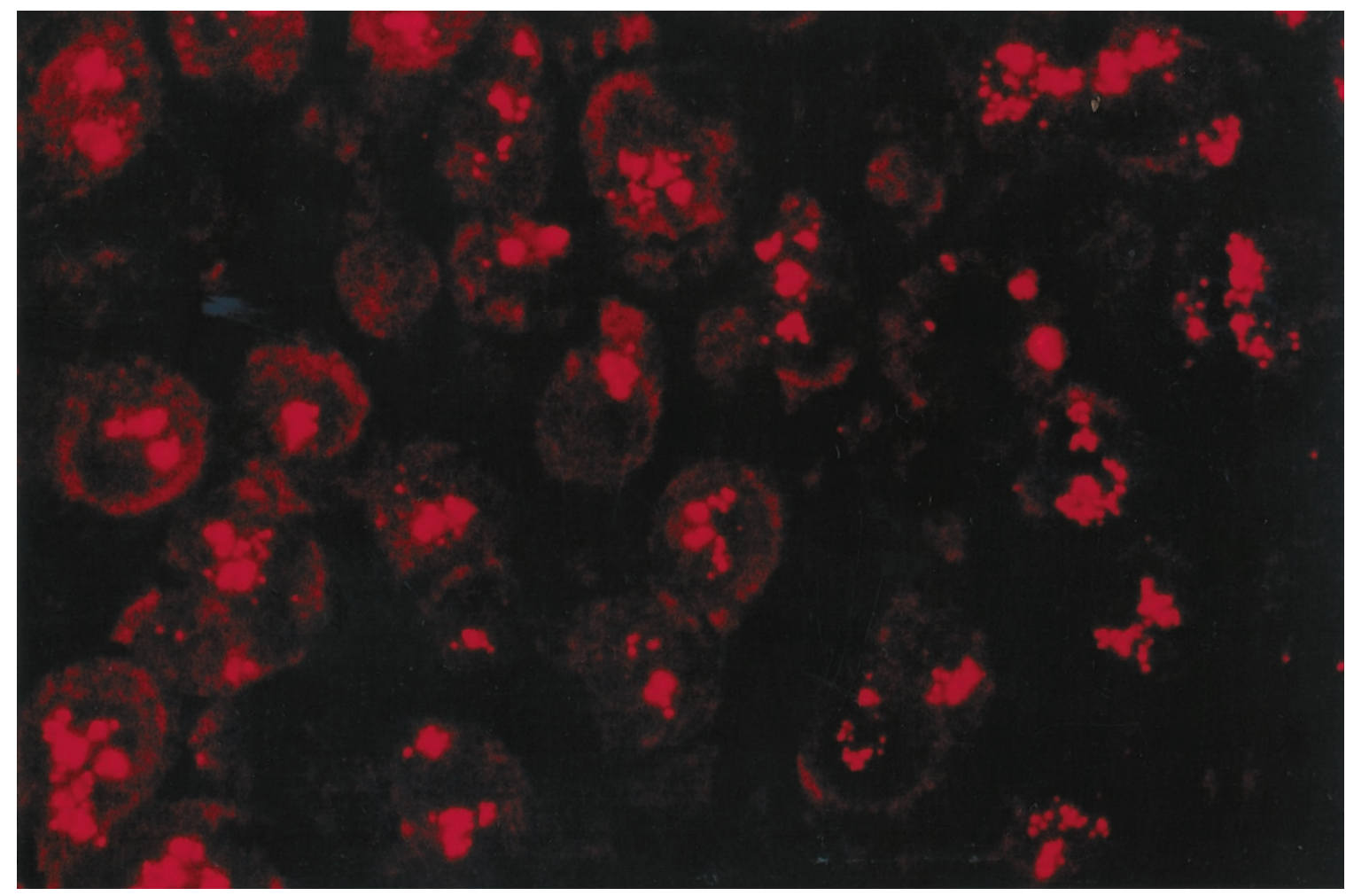

FIGURE 4. Invasive ductal carcinoma showing clusters of HER-2/neu signals in tumor cell nuclei using FISH.

TABLE 2. HER2/neu Expression and Nodal Status in Invasive Breast Cancer

\begin{tabular}{llc}
\hline & Nodal Status & HER2/neu Positive No. (\%) \\
\hline Invasive cases (220) & Positive 78 & $17(22)$ \\
& Negative 113 & $14(12.5)$ \\
& Not done 29 & $5(17)$ \\
Primary invasive (207) & Positive 75 & $16(21)$ \\
& Negative 104 & $13(13)$ \\
& Not done 28 & $5(18)$ \\
Recurrences (13) & Positive 3 & $1(33)$ \\
& Negative 9 & $1(11)$ \\
& Not done 1 & $0(0)$ \\
\hline
\end{tabular}

appropriate method of expressing the HER-2/neu status rather than using the scoring system of $1+$ $2+3+$ since the latter can be confusing because of different definitions by different groups. In addition, the intensity of IH can be manipulated by modifying the immunohistochemical technique. The assessment of the percentage of positive cells, although subjective, is reproducible as pathologists are trained to assess other biological markers e.g., estrogen and progesterone receptors in a similar fashion.

Concerns related to the high rate of "false positive" results by the HercepTest were expressed by Roche et al. (17). Although the HercepTest provides the opportunity to strictly adhere to a unified methodology by the users, it is relatively expensive and there are concerns regarding the clinical significance of the $2+$ positive group. This was further substantiated by Tubbs et al. (18) who showed that
$15 \%$ of cases that were $2+$ positive by HercepTest did not show gene amplification by either FISH or by mRNA detection.

Mass et all (15) showed that the cases scored as $2+$ in the CTA were found to have gene amplification using FISH in only $24 \%$ of cases as compared with $89 \%$ in the $3+$ cases confirming the high false positive rate in the $2+$ category. Moreover, the cases that had the $3+$ score showed significant response to Herceptin and Taxol or Adriamycin and cyclophosphamide (AC) when compared with $2+$ cases (3). These results indicate that the Herceptest is specific but too sensitive and that the $2+$ score ( $10 \%$ weak to moderate complete membrane staining) include a subset of tumors that do not have HER-2/neu gene amplification.

From the study of Jacobs et al. (19) it is reasonable to conclude that experienced labs using the same antibody with different methodologies and scoring methods can obtain concordant and reasonable results ( $97 \%$ concordance). Attempts to standardize scoring of IH staining in general and specifically for HER-2/neu were adopted by Allred et al. (20). The score of 1-5 incorporates the intensity of staining and the percentage of positive cells. Using that scoring methodology Molina et al. showed that there was good concordance between IH and Western blotting data and that both methods showed prognostic significance (21).

The variability of specificity and sensitivity of the various antibodies has been addressed by Pauletti 
et al. in 1984 (5) and by Penault-Laurca (4) and recently O'Malley (22). The latter study showed the high specificity of CB11, TAB250 and HercepTest $(97 \%, 95 \%, 82 \%)$ and the sensitivity of these three antibodies $(73 \%, 81 \%, 92 \%)$. The positive predictive value of HercepTest, however, was low at $63 \%$ compared with TAB250 at $84 \%$ and CB11 at $91 \%$.

In our study there was excellent overall concordance between IH and differential PCR for assessing HER-2/neu status in 235/250 cases of in situ and invasive breast cancer, (94\%) [IH+/PCR+ (16\%) and IH-/PCR- (78\%)]. In the invasive cancers (220 cases) the overall concordance between $\mathrm{IH}$ and PCR was $95 \%$. The sensitivity was $91 \%$ and the specificity was $96 \%$. Similar results correlating PCR and IH were obtained by P. Decremoux (23) and O'Malley (22).

FISH was useful in resolving some of the discrepancies between IH and differential PCR in the 11 discordant cases of invasive carcinoma. Three of the 11 discrepant cases were IH +ve/PCR -ve and FISH + ve indicating that the PCR was a false negative result. All three cases showed few nests of tumor cells surrounded by abundant stroma. The excessive amount of normal tissue compared with the tumor could account for the false negative PCR results. PCR and FISH were positive in two cases, whereas IH was negative indicating a false negative IH result. In these two cases the HER-2/neu copy number by FISH was low (i.e., five to six copies) suggesting that in cases with low level amplification $\mathrm{IH}$, on formalin fixed material may be negative or weak. The six remaining discrepant cases were IHve/FISH -ve but PCR + ve indicating a false positive PCR result. This is difficult to explain but may be due to technical aspects of PCR. It is possible that real time PCR could overcome this problem (24).

Pauletti et al. (5) using the Vysis probe found FISH to be highly sensitive $(96.5 \%)$ and specific $(100 \%)$ as compared with IH on frozen tissue. Similar results were obtained by Mitchel et al. (25). Press et al. (26) found FISH to be $98 \%$ sensitive and $100 \%$ specific compared with PCR and that FISH results were an independent predictor of poor outcome. Similar data showing concordance between $\mathrm{IH}$ and FISH were obtained by P. Jimminez et al. (27) and Jacobs et al. (28). These studies suggest that very few cases $(3-5 \%)$ show protein overexpression without gene amplification indicating that FISH or PCR could be false negative in about $5 \%$ of cases.

The percentage of cases with HER-2/neu amplification or over-expression varies considerably in the literature from as low as $10 \%$ to $54 \%$ (1). Our overall frequency of HER-2/neu over-expression/ amplification in invasive cancer was $16 \%$. The frequency detected in the node positive patients was $22 \%$ and in the node negative patients $12.5 \%$. The latter group was predominant in our series. The higher percentage positivity in the node positive patients supports the more aggressive behavior of the HER-2/neu positive tumors.

In summary, we have demonstrated that IH using CB11 is a reproducible, sensitive and specific method for assessing HER-2/neu status in breast cancer. The current study indicates that moderate or strong complete membrane staining in $\geq 10 \%$ of tumor cells in formalin fixed paraffin embedded tissue sections provides the appropriate cut off point when compared with PCR and FISH. IH is easily applicable in most laboratories and is relatively inexpensive. Routine use of FISH for HER-2/ neu testing that recently has been advocated by Slamon at ASCO2000 (Slamon D, personal communication) is not practical for a widely required test for breast cancer management since FISH is expensive and only available in large specialized labs. Positive and negative IH controls should always be performed and all cases with indeterminate results should be reassessed by either FISH or PCR in the specialized laboratory providing this service. Clinical validation with outcome data would strengthen our proposed practice of using $\geq 10 \%$ complete, moderate strong membrane staining as a positive cut off for IHC testing for HER-2/neu oncoprotein over-expression.

\section{REFERENCES}

1. Hanna WM, Kahn HJ, Trudeau M. Evaluation of HER-2/neu (erbB-2) status in breast cancer: from bench to bedside. Mod Pathol 1999;12:827-34.

2. Ross JS, Fletcher JA. The HER-2/neu oncogene in breast cancer: prognostic factor, predictive factor, and target for therapy. Stem Cells 1998;16:413-28.

3. Slamon D, Leyland-Jones B, Shak S, Paton V, Bajamonde A, Fleming $\mathrm{T}$, et al. Addition of Herceptin ${ }^{\mathrm{TM}}$ (humanized antiHER2 antibody) to first line chemotherapy for HER2 overexpressing metastatic breast cancer (HER2+/MBC) markedly increases anticancer activity: a randomized, multinational controlled phase III trial. Proc ASCO 1998;17:98a.

4. Penault-Llorca F, Adelaide J, Houvenaeghel G, Hassoun J, Birnbaum D, Jacquemier J. Optimization of immunohistochemical detection of ERBB2 in human breast cancer: impact of fixation. J Pathol 1994 173;65-75.

5. Pauletti G, Godolphin W, Press M, Slamon D. Detection and quantitation of HER-2/Neu gene amplification in human breast cancer archival material using fluorescence in situ hybridization. Oncogene 1996;13:63-72.

6. Bianco AR, De Laurentis M, Carlomagna C, Lauria R, Petrella G, Panico L, et al. 20 year update of the Naples Gun trial of adjuvant breast cancer therapy: evidence of interaction between c-erb-B2 expression and tamoxifen efficacy. Proc Am Soc Clin Oncol 1998;17:97a.

7. Elledge RM, Green S, Ciocca D, Pugh R, Allred DC, Clark GM, et al. HER-2 expression and response to tamoxifen in estrogen receptor-positive breast cancer: a Southwest Oncology Group Study. Clin Cancer Res 1998;4:7-2.

8. Pietras RJ, Poen JC, Gallardo P, Wongvipat N, Lee HJ, Slamon DJ. Monoclonal antibody to HER-2/neu receptor modulates repair of radiation-induced DNA damage and enhances ra- 
diosensitivity of human breast cancer cells overexpressing this oncogene. Cancer Res 1999;59:1347-55.

9. Pegram MD, Finn RS, Arzoo K, Beryt M, Pietras RJ, Slamon DJ. The effect of HER-2/neu overexpression on chemotherapeutic drug sensitivity in human breast and ovarian cancer cells. Oncogene 1997;31:15:537-47.

10. Reid MC, Lachs MS, Feinstein AR. Use of methodological standards in diagnostic test research. JAMA 1995;274:645-51.

11. Press MF, Hung G, Godolphin GW, Slamon DJ. Sensitivity of Her-2/neu antibodies in archival tissue samples; potential source of error in immunohistochemical studies of oncogene expression. Cancer Res 1994;54:2771-7.

12. Thor AD, Berry AD, Budman DR, Muss HB, Kute T, Henderson IC, et al. ErbB2, p53 and efficacy of adjuvant therapy in lymph node positive breast cancer. J Natl Cancer Inst 1998; 90:1346-60.

13. Paik S, Bryant J, Park C, Fisher B, Tan-Chiu E, Hyams D, et al. erbB-2 and to doxorubicin in patients with axillary lymph node-positive, hormone receptor-negative breast cancer. J Natl Cancer Inst 1998;90:1361-70.

14. Allred DC, Swanson PE. Testing for erbB-2 by immunohistochemistry in breast cancer. Am J Clin Pathol 2000;113: 171-5.

15. Mass R, Sanders C, Charlene K, Johnson L, Everett T, Anderson $\mathrm{S}$. The concordance between the clinical trials assay (CTA) and fluorescence in situ hybridization (FISH) in the Herceptin Pivotal Trials [abstract]. Proc ASCO 2000;19:291.

16. Keshegian AA, Caan A. erbB-2 oncoprotein expression in breast carcinoma poor prognosis associated with high degree of cytoplasmic positivity using CB-11 antibody. Am J Clin Pathol 1997;108:456-63.

17. Roche PC, Ingle JN. Increased HER2 with US Food and Drug Administration-approved antibody. Am J Clin Oncol 1999; 17:434-5.

18. Tubbs RR, Stoler M, Pettay J, Roch P, Grogan T. Apparent false-positive Hercept test results for HER-2/neu -A detailed evaluation of oncogene amplification including assessment of mRNA expression. Modern Pathol 2000;13(3):34A Abstract 180.

19. Jacobs TW, Gown AM, Yaziji H, Banes MJ, Schnitt SJ. Her$2 /$ neu protein expression in breast cancer evaluated by im- munohistochemistry. A study of interlaboratory agreement. Am J Clin Pathol 2000;11:171-5.

20. Allred DC, Harvey JM, Bernardo M, Clark GM. Prognostic and predictive factors in breast cancer by immunohistochemical analyses. Mod Pathol 1998;11:155-68.

21. Molina R, Ciocca DR, Tandon AK, Allred DC, Clark GM, Chamness GC, et al. Expression of HER-2/neu oncoprotein in human breast cancer: a comparison of immunohistochemical and Western blot techniques. Anticancer Res 1992; 12:1965-71.

22. O'Malley FP, Julian N, Arreson S, Tjan S, Whelan T, Blackstein M, et al. Comparison of HER2/neu status evaluated by immunohistochemistry and quantitative PCR. Mod Pathol 2000;13(3):29A, Abstract 149.

23. de Cremoux P, Martin EC, Vincent-Salomon A, Dieras V, Barbaroux C, Liva S, et al. Quantitative PCR analysis of c-erb B-2 (HER2/neu) gene amplification and comparison with p185(HER2/neu) protein expression in breast cancer drill biopsies. Int J Cancer 1999;83:157-61.

24. Bieche I, Onody P, Laurendeau I, Olivi M, Vivand D, Lidereau $\mathrm{R}$, et al. Real-time reverse transcription-PCR assay for future management of ERBB2-based clinical applications. Clin Chem 1999;45:1148-56.

25. Mitchell MS, Press MF. The role of immunohistochemistry and fluorescence in situ hybridization for HER2/neu in assessing the prognosis of breast cancer. Semin Oncol 1999; 26:108-16.

26. Press MF, Bernstein L, Thomas PA, Meisner LF, Zhou J-Y, Ma $\mathrm{Y}$, et al. Her-2/neu gene amplification characterized by fluorescent in situ hybridization: poor prognosis in nodenegative breast carcinomas. J Clin Oncol 1997;15:2894-904.

27. Jimenez RE, Wallis T, Tabasczka P, Visscher DW. Determination of Her-2/Neu status in breast carcinoma: comparative analysis of immunohistochemistry and fluorescent in situ hybridization. Mod Pathol 2000;13:37-45.

28. Jacobs TW, Gown AM, Yaziji H, Barnes MJ, Schnitt SJ. Specificity of HercepTest in determining Her-2/neu status of breast cancers using the United States Food and Drug Administration-approved scoring system. J Clin Oncol 1999; 17:1983-7. 